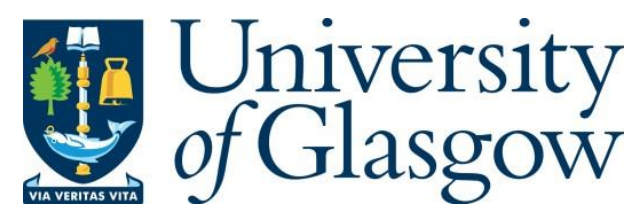

O'Neill, J. (2020) Case for persuasion in parental informed consent to promote rational vaccine choices. Journal of Medical Ethics, (doi: 10.1136/medethics-2020-106068).

There may be differences between this version and the published version. You are advised to consult the publisher's version if you wish to cite from it.

http://eprints.gla.ac.uk/215470/

Deposited on: 7 May 2020

Enlighten - Research publications by members of the University of Glasgow http://eprints.gla.ac.uk 


\title{
The Case for Persuasion in Parental Informed Consent to Promote Rational Vaccine Choices
}

\begin{abstract}
There have been calls for mandatory vaccination legislation to be introduced into the United Kingdom in order to tackle the national and international rise of vaccine-preventable disease. Whilst some countries have had some success associated with mandatory vaccination programmes, the Royal College of Paediatrics and Child Health $(\mathrm{RCPCH})$ insist this is not a suitable option for the United Kingdom, a country which has seen historical opposition to vaccine mandates. - There is a lack of comprehensive data to demonstrate a direct link between mandatory vaccination legislation and increased uptake. Whilst there are examples whereby there has been an improvement, some studies suggest that comparable results can be obtained by strongly recommending vaccinations instead. The RCPCH insist that Healthcare Workers (HCW) are ideally placed to engage and inform parents to make every interaction a "vaccine opportunity". This paper calls for a principled, rational approach to interpretations of autonomy which underpin parental informed consent. MacLean's concept of mutual persuasion could be a vehicle to ensuring parents are suitably informed of both the material risks associated with vaccine choices and to consider the rationality of their decisions, whilst ultimately upholding parental autonomy. It is argued that this, alongside infrastructural improvement, could create a more sustainable, long-term improvement in childhood vaccination rates in the United Kingdom than mandatory vaccination.
\end{abstract}

\section{Introduction}

Whilst Health Secretary Matt Hancock recently called for the "bold action" of mandatory vaccination in the United Kingdom [1], there is a lack of comprehensive data to demonstrate a direct link between mandatory vaccination legislation and increased uptake. Although there 
are examples whereby there has been an improvement, some studies suggest that comparable results can be achieved by strongly recommending vaccinations instead [2][3]. The House of Lords voiced their opposition by stating that "mandatory vaccination is not the way forward" [4] and instead recommended that healthcare workers [HCW] facilitate improved vaccine uptake through improved communication with parents [4] [5]. This mirrors the stance of the Royal College of Paediatrics and Child Health $(\mathrm{RCPCH})$ in calling for a "co-ordinated approach" so that "every contact between a child and healthcare worker .. be a vaccine opportunity" [6]. The RCPCH have warned that mandatory legislation fails to address the underlying cause of poor vaccine-uptake, namely poor accessibility and parental anxieties [4] [7] and would likely back-fire to create "determined vaccine-refusers...". The RCPCH have also warned that whilst "compulsion may work for some countries, it's not for us" [8].

Healthcare workers $[\mathrm{HCW}]$ have an opportunity to engage parents on the issue of vaccination when gaining consent. Informed consent is a fluid, ongoing process and early discussions about vaccination may commence long before appointments are made. In the informed consent process, those with capacity consider information to make an autonomous decision relating to medical intervention. There is no legal requirement for that decision to be rational [9]. Yet principled interpretations of autonomy concede that autonomous decisions should also be rational. Whilst irrationality may be acceptable for adult patients willing to bear the consequences of their own decisions [10], in the case of parental decision-making on behalf of a child, it is reasonable to argue that a legal duty should exist to facilitate rationality in parental informed consent. Parental decision-making exists on the premise that the child's best interest takes precedence, yet in the case of vaccinations, parents may struggle to determine those best interests amid the myriad of information and misinformation. As US Judge Mr. Justice Rutledge once said - “..parents may be free to become martyrs themselves, but it does not follow that they are free .. to make martyrs of their children" [11]. This paper considers a new legal standard, incorporating MacLean's model of mutual-persuasion in informed consent, as a way to facilitate rationality in parental decision-making in issues such as vaccination [9]. When combined with infrastructural improvement, this could present a 
more sustainable alternative to mandatory vaccination whilst upholding parental autonomy [4][12].

\section{The Re-emergence of Vaccine-Preventable Disease}

There has been parental suspicion of vaccination ever since Edward Jenner made his contribution to medical science over 220 years ago. In the mid-to-late 1800s, the original "anti-vaxxers" - the Anti-Vaccination Leagues - were created to protest against compulsory vaccination provisions held under the Vaccination Acts of 1853 and 1867. Their right to conscientious objection - or exemption - was finally recognized in the subsequent Act of 1898 [13] [14]. Such exemption clauses, which are often still incorporated into vaccine mandates to this day, can threaten to undermine the entire vaccine mandate strategy. Measles illustrates this point particularly well. Falling confidence in the Measles vaccine, and subsequent reduction in uptake, contributed to a $30 \%$ global resurgence in Measles cases in 2018 [15]. In New York State, where the vaccine is mandatory, a community with high levels of exemption was the source of an outbreak in the Spring of that year, which led to the declaration of a State of Emergency [16] [17].

When a population acquires a level of immunisation, whether that be through prior exposure to the pathogen or through immunisation programmes, it reduces the pool of hosts available to the pathogen. This can reduce transmission and indirectly protect unimmunised members of society through what is known as 'herd immunity'. Unimmunised members of society often include vulnerable groups such as; the immunocompromised, or those who cannot be vaccinated due to allergy or on account of their age, such as very young children. Measles is one of the leading causes of global child mortality in the under 5 s and can cause severe, longterm and debilitating complications [7]. In some areas of the UK, coverage with the first dose of the Measles Mumps and Rubella (MMR-1) triple vaccine plummeted to as low as $74.3 \%$ in 2018-19 [18]. This is of particular concern, as in 2017 when coverage of MMR-1 fell to $86 \%$ in Romania, it was soon followed by deadly measles epidemic which bore witness to 50,000 cases and 59 deaths [7][19]. Whilst Measles serves as a strong representation of the 
consequences of low vaccination coverage, last year uptake across all routine child vaccines fell in the UK [20]. This included reduced rates of immunisation with DTaP/IPV/Hib/HepB, also known as the '6-in-1' vaccine, leaving children exposed to the risk of contracting diphtheria, pertussis, tetanus, polio, hepatitis $\mathrm{B}$ and disease caused by Hameophilus Influenzae (Type b) [20].

\section{Parental Rights of Autonomy}

For each childhood vaccination to be administered, informed consent must be obtained. Where a child lacks the requisite capacity, such consent must be sought from those with parental responsibility [21][22]. The moral authority for parental responsibility "depends ...[upon] the entirely reasonable supposition that parents will act in the best interests of their children" [23]. The legal authority, arising from the Children act 1989 Part 2(2), upholds such “.. rights, duties, powers, responsibilities and authority..”[24] which should be used the child's best interests only. These rights are supported by the European Convention of Human Rights (ECHR) through Article 8 which upholds “...the right to respect for private and family life..” [25]. As a qualified right this can be limited “..such as is in accordance with the law and is necessary...for the protection of health...or ..the rights and freedoms of others" [26] such as the child, or others in society. The provisions of Article 8 of the European Convention on Human Rights (ECHR) recognise individual rights of autonomy in medical decision-making, yet crucially interpret autonomy in a manner which must give due consideration to others in society. This reflects a principled, rational interpretation of autonomy which will be addressed later.

The current legal standard for medical consent, established in Montgomery v Lanarkshire HB [2015][27], focuses upon information disclosure with an emphasis upon disclosure of material risks. Whilst undeniably important, such duty is purely informative. There is no corresponding duty to ensure decisions are rational. MacLean argues that in order to truly respect autonomy, decision-makers must consider the rationality of their decisions [9]. On 
that basis, MacLean proposes that the decision-making process should include a legal duty placed upon HCWs to persuade patients to make rational decisions, whilst the patient ultimately makes the final decision. This, he says, can ensure patients have both fully understood the material risks and are aware of the rationality of their decision; and that by doing so offers better protection of autonomy.

Autonomy ('Auto' is Greek for 'self' and 'nomous' is law) is a principle of self-governance. It is central to decision-making, yet its interpretation is subjective. Liberal views of autonomy, such as presented by Locke, hold that we should be afforded the "...freedom to order [our] actions...as [we] think fit...without asking leave, or depending on the Will of any other Man [28]". This uninhibited right to freedom considers only self-interests in decisionmaking [29], describing the patient's right to pursue their own ends without medical interference, or question, even if it seems irrational. Liberal parents will hold their freedom of thought in highest regard, often considering their parental instinct to be superior to medical knowledge [29]. Yet such reasoning is fundamentally flawed as it fails to consider the impact one's decision may have upon others. We do not exist in isolation, just as disease does not exist in isolation. Stirrat et al argue that liberalism fails to recognise bonds of society and community [30], whilst Mill's example of a dangerous bridge further illustrates that we are duty-bound by humanity to at least challenge irrational decisions. He states “..it would be a great misunderstanding of this doctrine to suppose [that we] should not concern [ourselves with].. the well-doing or well being of one another...." [31] . Ultimately a liberal parent's decision not to vaccinate their child also does not exist in isolation as it could eventually impact upon the health of another parent's immunocompromised child [29] [32]. Under European Law, such liberal constructs of autonomy are also rejected. Parental rights and those of medical autonomy held under ECHR Article 8 may be limited where they interfere with the rights of others [26].

Even Kant's classical liberalism, which upholds that one is autonomous when their actions are free from external influence, has a caveat to recognise that individuals are inextricably 
bound into the fabric of greater-society. Kant's test of rationality, the categorical imperative [33], requires one to "...act only according to that maxim by which you can at the same time will that it should become a universal law" [34]. This requires the individual decision to be one which could be intended to be applicable to all, so that we hold ourselves to the same standards as others. If we therefore accept autonomy as a principled, relational concept which gives consideration to society, then, as argued by Maclean it "seems reasonable that the decision-maker should depend on others for support and assistance..[p]rovided the responsibility remains with the patient" [9]. This would enable autonomous parents to seek support from HCWs in their decision-making. On that basis, it would also be reasonable to assume that HCWs could support rational autonomous parental decision-making by offering advice which gives consideration to the universal law. On the issue of vaccination, HCWs should be able to offer information relating to wider societal impacts of decisions and in doing so promote rationality. On this basis, informed consent, therefore, should be more educationally intensive for all involved. For example, in applying Kant's maxim; if one parent refused child vaccination, then in applying the test of universal law, all parents could refuse vaccinations. As a result, diseases could re-emerge in an era of ever-growing drug resistance, which could put the whole of society at risk.

Maclean goes further to argue that if we are to truly support a principled, rational construct of autonomy, HCWs should be under a legal duty to go further and persuade patients, or in this case the parent, on how best to meet a child's best interests. Persuasion can refer to influences upon decision making which "appeal to...self-interest ..[or a]...sense of social obligation./.or both" which can lead to the achievement of a "collectively valued goal" [35]. Such a collectively valued goal would be the health of all children in our society

Importantly, Anderson et al recognize that there is a spectrum of treatment pressures from persuasion to coercion, and the fine line must be recognized in practice [40]. However, at an individual and public health level, persuasion may be more acceptable, as it recognizes individual autonomy and concerns whilst putting the case forward for the overall benefits of a 
course of action [40]. Furthermore, such supportive persuasion would not amount to external influence as the parent would retain ultimate responsibility and could, according to MacLean similarly engage in persuading the HCW [9]. Persuasion should be a 'two-way street', whereby the patient, in demonstrating understanding and rationality could also persuade the $\mathrm{HCW}$ to consider their perspective. This somewhat reflects the court's approach in cases of parental dispute over vaccination whereby the courts have welcomed the chance to be persuaded by the dissenting parent [41].

\section{Information Disclosure in Informed Consent to Facilitate Best Interests Decisions}

The common law standard pertaining to consent focuses upon whether a doctor adequately informs the patient [27]. Maclean argues that as a result, the doctor's duty is to simply bestow information without influencing by way of professional opinion and so the patient is left "..to their fate" [9]. He argues that it is unrealistic to expect information to be relayed in a way that does not hold some bias; the order of words, the tone of voice and the doctor's own research influences and experiences are all likely to combine to influence how the patient receives and therefore process that information. In Mills $\mathrm{v}$ Oxford University Hospitals NHS Trust [2019] Steyn J accepted that "there should be a dialogue between the doctor and the patient, and it is important the advice should be comprehensible" [42]. One could, therefore, argue that to ensure a patient has understood the information provided requires a dialogue - one which goes beyond simple disclosure. This amounts to a duty to ensure the patient has awareness of risk [43]. In accepting the proposition that material risks are subjective to each patient an open dialogue is key to determining which risks are material. Such a dialogue should be subject to persuasion from either party.

When confronted with negative information, it is an evolutionary instinct to focus upon risk, rather than benefits [44]. This is where dialogue and HCW communication skills are vital. Research has shown that parents do not feel they have enough time to fully discuss their 
vaccine concerns [45] and even pro-vaccine parents do not feel they received sufficient information and often question their choices [46]. Those for whom dialogues with HCWs are insufficient are more likely to seek their own information, usually from internet sources or other parents [46]. NHS England chief recently condemned the school gates as the "...breeding grounds..." for "vaccine myths" [47]. This is the kind of "willful disinformation' [47] which should be addressed directly through informed consent dialogues by 8recognising parental concerns and providing evidence-based information. For those parents who are complacent [48] engaging in early discussions could be an opportunity for engagement.

MPs have discussed the need for “..better training of health professionals on what vaccines are, what they do, how they work and what is in them so that those professionals are ably equipped to answer parents' questions" [49]. These recommendations reflect the need for improved information disclosure and trust to reach the Montgomery standard, and beyond. In the case of vaccination, it is reasonable to conclude that upon a test of materiality - namely that a reasonable person in that parent's position would attach significance to that risk - that the HCW should inform the parent as to the risk of side effects and the risk that nonvaccination poses in terms of disease and its associated complications. Whilst, in reflecting a rationalized approach to autonomy, the parent would be informed of the wider risk of disease in the community, such as that concerning immunocompromised groups, the loss of herd immunity and the consequential rise of disease re-emergence which could be resistant to treatments. By providing such information the parent should consider the impact individual vaccine choices have upon others, which may then induce - not coerce - not only better determination of their child's best interests, but a sense of civic duty amongst parents to have their children vaccinated. Whilst the law recognises that decision making should be free from coercion, Anderson et al 2016 consider that persuasion is a more socially acceptable construct which assists the patient in determining the best course of action to meet their best interests, whilst retaining the right to decide [40]. This could greatly assist parents in 
determining their child's best interests as vaccine hesitancy often arises from an uncertainty over the best course of action in order to best serve those best interests of the child.

\section{Working Together to Determine Best Interests}

The GMC advises that "Doctors should always act in the best interests of children and young people...[therefore] assessment of best interests will include...the views of the child...so far as they can express them, [and]..the views of parents" [50]. This indicates that the GMC hold that the determination of the child's best interests may be determined by parental opinions, which requires active dialogue and a degree of persuasion from the parents. Yet, as research has shown many parents remain uncertain over whether they hold the correct views in relation to vaccination. This further raises the issue of whether there should be an additional legal duty placed upon doctors to persuade parents as to why vaccination is in the child's best interests. The State and those employed by it, are duty-bound to uphold the child's right to the "enjoyment of the highest attainable standard of health..." which includes the duty to "combat disease..." and “..develop preventive health care" according to Article 24 of the United Nations Convention on the Rights of the Child (UNCRC) [51]. In practice, such a legal duty of persuasion would reflect current GMC guidance that consent is a "process of discussion and decision-making..” [36] rather than the end result of information disclosure alone, which MacLean argues can "abandon ...patients].. to their choices" [9]. Enhanced engagement with parents, during the consent process, can facilitate greater understanding of parents' values and beliefs. This will allow HCWs to better support treatment choices and may help avoid the pitfall of defensive medicine by enhancing, rather than eroding, the practitioner-patient relationship. At law, there is no obligation for patients to explain irrational treatment choices [10] yet it may arguably be justifiable for such a new legal duty to require engagement with parents on irrational choices which may affect a child's health. Where parents adamantly refuse to engage, MacLean suggests that the legal duty upon HCWs to support decision-making in this way, would then be discharged [9]. Whilst determined parental refusal may be a potential barrier to this approach, recent statistics 
suggest that the percentage of parents refusing vaccines fell from $11 \%$ in 2015 to $8 \%$ in 2019 , which could indicate an openness to persuasion within that demographic [37].

As parents may hold concerns relating to vaccinations, so too may HCWs. This may affect their ability to meet the legal standard of persuasion. However, existing GMC guidance advises HCWs not to burden vulnerable patients with personal beliefs. One option may be to utilize existing guidance for professional conscientious objection. This would enable HCWs to refer patients on to alternative, more suitable, practitioners when they feel unable to provide such treatment or evidence-based information [38]. In practice, the legal duty of persuasion would expand upon the current standards of disclosure in informed consent and time spent engaging with parents viewed as an investment in both the future health of the child and wider public health. Such discussions will require HCWs to have more specialist knowledge of vaccines, their safety and ongoing post-marketing surveillance. In recognizing that $a$ "..high level of knowledge and a positive attitude to immunization in [HCWs] are ...important determinants in achieving and maintaining high vaccine update” ... Public Health England (PHE) have already developed a Core Curriculum for Immunisation Training which ensures "immunisers are confident, knowledgeable and up-to-date" through a process of continuing professional development, evidence-based practice and revalidation [39].

Where the domestic courts have taken the role of judicial parent on the issue of vaccination, the priority has been to fulfil the child's welfare interests [41]. The courts have been clear they are not there to make judgement as to whether vaccination is a good or bad concept [41]. However, through careful examination of expert witness testimony [52] and evidence-based information [53, the judiciary support the normative medical opinion that vaccination best fulfils the child's welfare needs by preventing disease. In Re C and F(Children)[2003], Sumner J emphaised that “...over 20 million doses of MMR have been delivered in the United States alone..if there were any real problems they would have emerged" [52]. The current precedent, therefore, illustrates that by allowing the child to enjoy the highest attainable level of health, vaccination meets the best interests of the child [54]. As judicial parent, the court 
has access to expert testimony and evidence-based information which many parents do not. By incorporating a legal duty of persuasion into parental decision-making, parents are likely to be better informed and educated about vaccine safety and efficacy so that they too can make decisions which meets their child's best-interests.

The European countries which have, thus far, implemented mandatory vaccination have witnessed associated rises in coverage rates. France, which has one of the highest levels of mistrust in vaccines, witnessed a rise in non-mandatory vaccination uptake following mandatory vaccination legislation [55]. Whilst it can be difficult to disentangle the effects of mandatory vaccination from the accompanying persuasive information campaigns, LévyBruhl et al 2018 suggest success may stem, not from the mandate itself, but from better informing parents [55]. This could further support the premise that better communication with parents could yield the desired results without the need for mandatory vaccine legislation. A policy of mandatory vaccination may not offer up the same educational opportunities that informed consent does and could miss the chance for engagement with parents on these key issues.

\section{Infrastructure to support Vaccine Uptake}

Whilst vaccination is voluntary, the aforementioned strategies rely upon engagement opportunities with parents which will depend upon improved infrastructure. The RCPHC recommends improvements be made to appointment and reminder systems alongside the implementation of adequate numbers of well-trained staff to discuss vaccinations with parents [56]. The necessity for these recommendations were also emphasized in a survey from the Royal Society for Public Health (RSPH) which recognised appointment issues as some of the biggest barriers to vaccination [57]. Current NHS IT systems are not robust enough to manage records and prompt reminders for the complex array of vaccines which make up the UK vaccination schedule [4][5]. For families with multiple children this current 
system represents a logistical barrier to vaccination which is further perpetuated by difficulty in aligning appointments with time off work and school. Whilst a system of mandatory vaccination could potentially see unvaccinated children excluded from school, the House of Lords argue that instead, schools should represent a positive opportunity to trigger vaccine reminders and catch children who might otherwise fall through the net [4].

As part of the NHS's "wider commitment to digitally transform" communication with patients, social media can be used to "empower the public to take charge of their own health and care" [58]. This could positively engage parents in order to address vaccine hesitancy. A recent NHS Digital scheme successfully addressed breast screening hesitancy in a community through a Facebook group. HCWs used the group to prompt reminders, offer advice on accessing services and to provide "quality information" to alleviate anxieties. The scheme resulted in a $12.9 \%$ increase in screening [59]. The importance of engaging parents early was highlighted by Enkel et al (2018) who argue that "clear, accurate and concise information backed by quality evidence, must be provided to parents, ideally as early as pregnancy [44]." Frequent visits to HCWs during antenatal and post-natal periods present early opportunities for vaccine discussion [60].

The Department for Health and Social Care (DHSC) and PHE, tasked with developing a specific strategy to tackle falling MMR coverage, may consider "other settings outside of the GP for vaccinations" [61]. A study by Anderson et al (2014) also showed that patients want more convenient access to vaccine services and prefer to visit community-based pharmacies than GP practices [62]. NHS Community Pharmacist Consultation Service aims to create "same-day, booked private consultations" with pharmacists which could provide convenient and effective access to information and vaccination, saving around 20 million annual GP appointments per year [63] [64]. Further access could be improved through the creation of specialized consent clinics [65] or utilization of previously successful mobile screening units [66]. 


\section{Conclusion}

Falling vaccination rates must be addressed if we are to avoid a harmful re-emergence of devastating childhood diseases. Mandatory vaccination legislation is not a sustainable solution as it is likely to be undermined by parental mistrust and exemption. Healthcare Workers are key in the frontline battle of improving vaccine confidence amongst parents through informed consent. Yet we must consider whether a parental decision-making ought to be rational. Liberalist constructs of autonomy have falsely led to the belief that decisionmaking should be self-serving, whilst principled autonomy requires rational decision-making, with consideration of others. The law of informed consent should too reflect a more principled construct of autonomy by including a legal duty to facilitate rationality by persuading patients to make rational decisions. Such a duty would expand upon the existing legal duty of information disclosure in informed consent by ensuring consent is a process of dialogue with parents, rather than the end result of information sharing. For parents, whose upmost consideration must be the best interests of their child, such persuasion would facilitate rational decision-making whilst upholding parental autonomy. Statistics suggest that the demographic of parental refusers may be falling, however, mandatory vaccination has the potential to damage parental trust and create more determined vaccine refusers. Conversely, persuasion is likely to enhance the practitioner-parent relationship, build confidence and is also likely invoke a sense of civic duty in favour of vaccination to create sustainable improvements. Supported by recommended infrastructural changes, HCWs could draw upon existing training opportunities and guidance to develop the skills and knowledge necessary to meet this new legal standard. 


\section{References}

1 Walker, P 'Hancock: Compulsory vaccinations beings seriously considered' 29 Sept 2019. The Guardian. Accessed at https://www.theguardian.com/society/2019/sep/29/governmentseriously-considering-compulsory-vaccinations-matt-hancock on 22 Dec 2019

2 Lee C, Robinson JL. 'Systematic review of the effect of immunization mandates on uptake of routine childhood immunizations. J Infect. 2016; 72, 659-666

3 Giard DZ. "Recommended or mandatory pertussis vaccination policy in developed countries: Does the choice matter? Public Health 2012; 126(2):117-22

4HL Deb | 14 May 2019 | vol 797 I col 70CG

5 HC Deb | 12 June 2019 | vol 661 | col 354WH

6 Royal College of Paediatrics and Child Health: RCPCH Responds to Prime Minister's Announcement on Immunisation, 19 August 2019. Accessed at

https://www.rcpch.ac.uk/news-events/news/rcpch-responds-prime-ministers-announcementimmunisation-uptake on 9 November 2019

7 Dascalu S. Measles Epidemics in Romania: Lessons for Public Health and Future Policy; Front. Public Health (2019)

8 Royal College of Paediatrics and Child Health: Vaccinations important and highly effective, says child health experts, 27 March 2019 accessed at https://www.rcpch.ac.uk/news-events/news/vaccinations-important-highly-effective-sayschild-health-expert on 9 November 2019

9 MacLean A. Autonomy, Consent and Persuasion. European Journal of Health Law 2006; $13: 321-338$

10 Re T (Adult: Refusal of Treatment) [1993] Fam 95 at [102], [1992] 3 WLR 782, 786.

11 Prince v Massachusetts [1944] 321 US 150 at [170]

12 MacDonald NE, Harmon S, Dube E, Steenbeek A, Crowcroft N, Douglas JO, Faour D, Leask J, Butler R. Mandatory infant \& Childhooh immunization: Rationales, issues and knowledge gaps; Vaccine 2018; 36(39):5811-5818

https://doi.org/10.1016/j.vaccine.2018.08.042

13 Williamson S. 'One hundred years ago: Anti-vaccination leagues' Arch Dis Child 1984; 59; $1195-1196$

14 Vaccination Acts of 1853, 1867, 1898

15 World Health Organisation Newsroom: Detail 'Measles cases spike globally due to gaps in vaccination coverage 29 November 2018 at https://www.who.int/news-room/detail/29-112018-measles-cases-spike-globally-due-to-gaps-in-vaccination-coverage Accessed on 22 Dec 2019 
16 Hopkins Tanne, J. 'New York City Mayor declares measles public health emergency' BMJ 2019; $365: 11724$

17 Clarke S, Giubili A, Walker M J. Conscientious Objection to Vaccination. Bioethics 2017;31(3): 155-161

18 NHS Digital Childhood Vaccination Coverage Statistics - Hackney and City of London, MMR I at 24 months update was $74.3 \%$. Accessed at NHS Digital Child Vaccination Coverage Statistics Interactive Resource available at https://app.powerbi.com/view?r=eyJrIjoiZTI3NWZhNzItMTIyZS00OWM2LTg0MzMtOGY 5YTJjMGY0MjI1IiwidCI6IjUwZjYwNzFmLWJiZmUtNDAx YS04ODAzLTY3Mzc0OGU2 MjllMiIsImMiOjh9 on 23 December 2019

19 Romanian National Centre for the Surveillance and Control of Communicable Diseases (CNSCBT) Weekly Report on Measles, Dec 212018 in Dascalu S. Measles Epidemics in Romania: Lessons for Public Health and Future Policy; Front. Public Health (2019)

20 NHS Digital Childhood Vaccination Coverage Statistics - England 2018-19. 26 Sept 2019 accessed at https://digital.nhs.uk/data-and-information/publications/statistical/nhsimmunisation-statistics/england-2018-19

\section{Family Law Reform Act 1969}

22 European Convention on Human Rights and Biomedicine 1997, Article 6(2)

23 British Medical Association Ethics Department: Parental Responsibility. Guidance from the BMA, October 2008 - states that "the moral authority behind parental responsibility depends in large part on the entirely reasonable supposition that parents will act in the best interests of their children".

24 Children Act 1989

25 European Convention on Human Rights, Article 8 (1) 'The Right to Private and Family Life'

26 European Convention on Human Rights, Article 8 (2) 'The Right to Private and Family Life'

27 Montgomery v Lanarkshire HB [2015] SC 11

28 Locke, 1960 [1689]: 287

29 Reich, J A. Neoliberal mothering and vaccination refusal: Imagined gated communities and the privilege of choice. Gender \& Society. 2014, 28(5), 679-704

30 Stirrat G M, R Gill. Autonomy in Medical Ethics after O’Neill. J Med Ethics 2005;31:127-130. doi: 10.1136/jme.2004.008292

31 Mill J S. 'On Liberty' (1859) in 'On Liberty and other Essays' (1998) Oxford University Press, Oxford, 84

32 Ikonomidis S, Singer P A. Autonomy, Liberalism and Advance Care Planning. J Med Ethics. 1999;25: 522-527

33 O'Neill O. Autonomy and Trust in Bioethics. Cambridge. Cambridge University Press, $2002,30,83-5$. 
34 Kant I. (1785) Grounding for the Metaphysics of Morals. In Ellington J W. (1981) 'On a Supposed Right to Lie Because of Philanthropic Concern' ( $3^{\text {ra }}$ Ed) Indianapolis, Indiana, Hackett Publishing Company

35 Bell S, Hindmoor A, Mols F. Persuasion as Governance: A State-centric Relational Perspective. Public Administration 2010;88(3):851-870

36 General Medical Council (2008) 'Consent: patients and doctors making decisions together'. Accessed at https://www.gmc-uk.org/static/documents/content/Consent English 0617.pdf on 13 April 2020

37 National Audit Office 2019. Investigation into pre-school vaccinations. (HC 100, 201920), London: NAO External Relations

38 General Medical Council, 'Personal Beliefs and Medical Practice'. Accessed at "https://www.gmc-uk.org/ethical-guidance/ethical-guidance-for-doctors/personal-beliefsand-medical-practice/personal-beliefs-and-medical-practice"on 13 April 2020

39 Public Health England, 'National Minimum Standards and Core Curriculum for Immunisation Training for Registered Healthcare Practitioners' Revised February 2018 Accessed at:

https://assets.publishing.service.gov.uk/government/uploads/system/uploads/attachment data /file/679824/Training standards and core curriculum immunisation.pdf on 13 April 2020

40 Anderson L. From Persuasion to Coersion: Responding to the Reluctant Patient in Rehabilitation. Phys Ther 2016; 96(8):1234-40

41 Re B(A Child: Immunisation)[2018] whereby Belamy LJ asserted that if the objecting parent was to provide evidence of an equivalent quality, which demonstrated that vaccines were not to be in the child's best interests, that would be considered.

42 Mills v Oxford University Hospitals NHS Trust, [2019] WL 015747742019 at [202] in considering Montgomery at [90]

43 Hendrix K S, Strum L A, Gregory D Z, Meslin E M. Ethics and Childhood Vaccination Policy in the United States. Am J Public Health 2016;106(2):273-278

44 Enkel S L, Attwell K, Snelling T L, Christian H E. Hesitant compliers': Qualitative analysis of concerned fully-vaccinating parents. Vaccine 2018;36(44)

45 McKee C. Exploring the Reasons Behind Parental Refusal of Vaccines. J Pediatr Pharmacol Ther. 2016; 21(2):104-109

46 Downs J S, de Bruine W B, Fischoff B. Parents' Vaccination Comprehension and Decisions. Vaccine 2008;26:1595-1607

47 Gayle D ‘School Gates Breeding Grounds for Vaccine Myths, Skas NHS Chief' The Guardian, 12 October 2019

48 Hornez Z, Powell D, Hummel J E, Holyoak K J. Countering Antivaccination Attitudes. Proc Natt Ac Sci USA 2015;112(33) 10321-10324

49 HC Deb |12 June 2019 | Col 342

50 GMC: 0-18 years: Guidance for all Doctors: Assessing Best Interests accessed at https://www.gmc-uk.org/ethical-guidance/ethical-guidance-for-doctors/0-18-years/assessingbest-interests 
51 United Nations Convention on the Rights of the Child, Article 24 s.s 1, 2c, $2 \mathrm{f}$

$52 \mathrm{Re} \mathrm{C}$ and F(Children) [2003] EWHC 1376 (Fam) as per Sumner J at [194] “...over 20 million doses of MMR have been delivered in the United States alone..if there were any real problems they would have emerged"

$53 \mathrm{Re} B$ (A Child) [2003] EWCA Civ 1148 as per Thorpe LJ at [20]

54 London Borough of Barrett v SL [2017] EWHC 125 (Fam)

55 Lévy-Bruhl D, Fonteneau L, Vaux S, Barret A, Antona D, Bonmarin I, et al. Assessment of the impact of the extension of vaccination mandates on vaccine coverage after 1 year, France, 2019. Euro Surveill. 2019;24(26):1900301

56 Royal College of Paediatrics and Child Health: Response to Research on Compulsory Vaccination. 17 May 2019

57 Royal Society for Public Health Report: 'Moving the Needle, Promoting Vaccination Uptake Across the Life Course' January 2019. Accessed at https://www.rsph.org.uk/uploads/assets/uploaded/3b82db00-a7ef-494c85451e78ce18a779.pdf on 23 Dec 2019.

58 NHS Digital Press Release. 'More women attend for Breast screening thanks to success of digital inclusion project.' 30 October 2018. Accessed at https://digital.nhs.uk/news-andevents/latest-news/more-women-attend-for-breast-screening-thanks-to-success-of-digitalinclusion-project On 12 November 2019

59 Information Services Division Scotland (ISD Scotland): Scottish Breast Screening Programme Accessed at http://www .isdscotland.org/Health-Topics/Cancer/Breast-Screening/ on 12 November 2019

60 NHS England. The Atlas of Shared Learning Case Study: Improving Vaccination Uptake by Changing the Way Pregnant Women Were Offered and Accessed Services, 18 July 2018. Accessed at https://www.england.nhs.uk/atlas case study/improving-vaccination-uptake-bychanging-the-way-pregnant-women-were-offered-and-accessed-services/ on 9 November 2019

61 Wickware C. News \& Analysis: NHS England to look at childhood vaccinations in healthcare settings other than general practice' The Pharmaceutical Journal online, 19 Aug 2019. I DOI: 10.1211/PJ.2019.20206968 Accessed at https://www.pharmaceuticaljournal.com/news-and-analysis/news/nhs-england-to-look-at-offering-childhoodvaccinations-in-healthcare-settings-other-than-general-practice/20206968.article

62 Anderson C, Thornley T. "It's easier in pharmacy": Why some patients prefer to pay for flu jabs rather than use the National Health Service. BMC Health Services Research 2014;14: 35

63 NHS England and NHS Improvement North East and Yorkshire: News: Community Pharmacy Pilot to Increase access to General Practice (24 July 2019). Accessed at https://www.england.nhs.uk/north-east-yorkshire/2019/07/24/community-pharmacy-pilot-toincrease-access-to-general-practice/ on 23 Dec 2019

64 Wickware C. Flu Vaccine Uptake Lower than 2017 for GPs while vaccination Numbers Surge for Pharmacists, The Pharmaceutical Journal 2019 DOI: 10.1211/PJ.2018.20205885 https://www.pharmaceutical-journal.com/news-and-analysis/news/flu-vaccine-uptake-lowerthan-2017-for-gps-while-vaccination-numbers-surge-for-pharmacists/20205885.article

Accessed on 9 November 2019 
65 NHS Wales. Good Practice in Consent Implementation Guide: Consent to Examination or Treatment: Seeking Consent for Anaesthesia (7). (2002) accessed at http://www.wales.nhs.uk/publications/impguide-e.pdf on 9 November 2019

66 Greenwald Z R, El-Zein M, Bouten S, Ensha H, Vazquez Franco E L. Mobile Screening Unit for the Early Detection of Cancer: A Systematic Review. Cancer Epidomiol Biomarkers Prev 2017;26(12):1679-1694 DOI: 10.1158/1055-9965.EPI-17-0454. 